\title{
A ressurreição da palavra
}

\section{The resurrection of the word}

Autor: Viktor Chklóvski Tradutores: Letícia Mei, Priscila Nascimento Marques, Raquel Toledo

Edição: RUS Vol. 11. N $^{\circ} 16$

Data: Setembro 2020 


\section{A ressurreição da palavra

\author{
Viktor Chklóvski \\ Tradução de Leticia Mei*, \\ Priscila Nascimento Marques ${ }^{* *}$ \\ e Raquel Toledo ${ }^{* * *}$
}

\section{Nota introdutória}

* Mestra e doutora pelo Programa de Pós-Graduação em Literatura e Cultura Russa, da Faculdade de Filosofia Letras e Ciências Humanas, Universidade de São Paulo. https://orcid.org/0000-0002-93151857; leticiamei@usp.br

** Mestra e doutora pelo Programa de Pós-Graduação em Literatura e Cultura Russa, da Faculdade de Filosofia Letras e Ciências Humanas, Universidade de São Paulo. Realiza estágio de pós-doutorado no mesmo programa;. https:// orcid.org/0000-0002-7111-6372; prinmarques@alumni.usp.br
O ensaio "A ressurreição da palavra" de Viktor Chklóvski (1893-1984) foi escrito a partir da palestra intitulada "O lugar do futurismo na história da língua", proferida pelo autor em 23 de dezembro de 1913 no café Bodriátchaia Sobáka ["Cão Vira-lata"], em São Petersburgo.

Nos manuscritos, Chklóvski elucida os objetivos de sua apresentação:

O objetivo da presente conferência é explicar os procedimentos da arte recente e mostrar que sua origem não está absolutamente no desejo de ser extravagante. [...] Os loucos [futuristas - A. G.] são clarividentes, eles sentem com os nervos doentes a catástrofe que se aproxima. [...] Os senhores negam a nova arte, sem conhecê-la, em nome de um antigo que sequer compreendem. Não precisamos das formas 
${ }^{* * *}$ Mestra pelo Programa de

Pós-Graduação em Literatura e Cultura Russa, da Faculdade de Filosofia Letras e Ciências Humanas, Universidade de São Paulo.

E-mail: rachtoledo@gmail.com antigas para expressar nossos sentimentos. [...] Em pátios estreitos o céu parece diferente. $O$ trem sobre a ponte exige novos ritmos [...] nós não fazemos caretas. O futurismo não é um círculo. [...] Virar o quadro para ver as tintas, ver como o artista enxerga a forma, não a narrativa. A palavra está ligada ao hábito, é preciso torná-la estranha para que ela esbarre na alma, para que ela interrompa. O epíteto como renovação da palavra. Nós retiramos a sujeira das pedras preciosas, despertamos a bela adormecida. O valor autônomo da palavra. Devolver à palavra o rosto e a alma. ${ }^{1}$

A publicação de "A ressurreição da palavra" foi o impulso inicial para a organização do grupo que posteriormente formaria a Sociedade para o Estudo da Língua Poética (OPOIAZ). Assim, este pode ser considerado, por um lado, um escrito pré-formalista e, por outro, um texto precursor de muitas ideias fundamentais da chamada Escola Formal dos estudos literários.

Neste ensaio, Chklóvski parte das ideias do teórico da literatura Aleksandr Vesselóvski (1838-1872) e do linguista e folclorista russo Aleksandr Potebniá (1835-1891): ambos observam na língua uma tendência em direção ao utilitarismo, à transitividade, ao reflexo em oposição à percepção viva e ao valor autônomo².

Essa visão, que também influenciou profundamente os simbolistas, ressoa com clareza no texto de Chklóvski, mas a partir de uma apreciação diversa. Em "A ressurreição da palavra", o autor propõe um retorno ao sentido primordial não como maneira de voltar às estruturas primitivas do pensamento, mas como meio de atualização estética, como procedimento poético de crítica do uso da língua ${ }^{3}$.

1 CHKLÓVSKI, 1990, p. 486-487. 0 trecho do manuscrito é apresentado na nota introdutória de Aleksandr Galúchkin dessa edição.

2 HANSEN-LÖVE, A. Russki formalizm: metodologuítcheskaia rekonstruktsiia razvítiia na osnove printsipa ostraniéniia. [Formalismo russo: reconstrução metodológica do desenvolvimento com base no princípio de ostraniénie]. Moscou: lazyki Russkoi Kultury, 2001.

3 HANSEN-LÖVE, A., 2001. Idem. 
De grande interesse é observar o diálogo entre o ensaio de 1914 e o "manifesto" formalista4 "A arte como procedimento", de 1917, no qual o autor consolida a ênfase na forma. Em "A ressurreição da palavra", ainda que parta da noção de imagem/ figuratividade ${ }^{6}$ presente em Potebniá, para Chklóvski ela não é uma forma de pensamento, mas de vivência, de sensação do material verbal. A experiência produzida pelo procedimento literário suscita uma reação que deve ser entendida de um ponto de vista sobretudo sensualista: "O que chamamos arte, então, existe para retomar a sensação da vida, para sentir os objetos, para fazer da pedra, pedra". ${ }^{7}$ A visão da pedra (em vez do mero reconhecimento) requer precisamente a "despetrificação" da palavra, mote do ensaio traduzido a seguir.

\section{A ressurreição da palavra ${ }^{8}$}

A palavra-imagem e sua petrificação. $O$ epíteto como um meio de renovação da palavra. A história do epíteto é a história do estilo poético. $O$ destino das obras dos antigos artistas da palavra é o mesmo que o destino da própria palavra: eles perfazem o caminho da poesia à prosa. A morte das coisas. A tarefa do futurismo - a ressurreição das coisas - é devolver ao homem a vivência do mundo. A ligação dos procedimentos da poesia futurista com os procedimentos de uma língua geral do pensamento. A língua semi-inteligível da poesia antiga. A língua dos futuristas.

\footnotetext{
4 Conforme expressão de Boris Eikhenbaum, em "Teoriia formalnogo metoda" [Teoria do método formal] (1925).

5 CHKLÓVSKI, 2019.

6 Vale observar que o adjetivo "figurado" em russo (óbraznii) tem em sua raiz o substantivo "imagem" (óbraz), de modo que a palavra figurada (óbraznoe slovo) é aquela que carrega uma imagem.

7 CHKLÓVSKI, 2019, p. 161.

8 A tradução foi feita diretamente do russo a partir da seguinte edição: CHKLÓVSKI, Viktor. Sobránie sotchiniénii. Tom I - Revoliutsiia [Obra reunida. Tomo 1 - Revolução]. Moscou: Novoe Literaturnoe Obozreniie, 2018.
} 
A mais antiga criação poética do homem foi a criação das palavras. Agora, elas estão mortas e a língua mais parece um cemitério, mas a palavra recém-nascida era viva, figurativa. Toda palavra é essencialmente um tropo. Por exemplo, "mês" [miéssiats]: o significado original dessa palavra é "medidor"; "desgraça" [góre] e "tristeza" [petchál] é o que queima e o que chamusca; a palavra "enfant" (assim como, no russo antigo, "adolescente" [ótrok]), significa ao pé da letra "não falante". Existem tantos exemplos assim quanto palavras numa língua. Com frequência, quando alcançamos a imagem perdida, apagada, que outrora jazia na base da palavra, ficamos estupefatos por sua beleza, beleza essa que existia e já não existe mais.

As palavras empregadas pelo nosso pensamento no lugar de conceitos gerais, quando servem de signos algébricos, por assim dizer, e devem ser não-figurativas, quando são usadas na fala cotidiana e não são ditas ou ouvidas até o fim, tornam-se habituais e suas formas interna (figurativa) e externa (sonora) deixam de ser vivenciadas. $O$ habitual não é vivenciado, não é visto, mas reconhecido. Não vemos as paredes de nosso quarto, temos dificuldade de perceber erros tipográficos durante a revisão, em particular, se o texto tiver sido escrito em um idioma que conhecemos bem, pois não podemos nos forçar a perceber, a ler em vez de "reconhecer" a palavra habitual.

Se quisermos criar uma definição de percepção "poética" e, em geral, de percepção "artística", de certo nos depararemos com a seguinte definição: a percepção "artística" é a que leva a vivenciar a forma (talvez não apenas a forma, mas ela certamente). A legitimidade dessa "definição de trabalho" pode ser demonstrada sem dificuldade nos casos em que uma expressão poética qualquer se torna prosaica. Por exemplo, é claro que a expressão "pé" da montanha ou "capítulo"g do livro ao passarem, da poesia à prosa, não tiveram seu sentido alterado, apenas perderam sua forma (nesse caso, a forma interna). 0

9 No original, a palavra glavá [capítulo] é um empréstimo semântico do eslavo antigo por

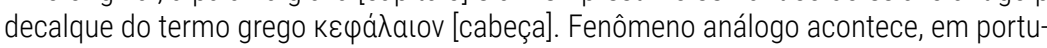
guês, com a palavra "capítulo" cuja origem é o termo latino capitulum, diminutivo de caput [cabeça]. 
experimento proposto por A. Gornfeld no artigo "Os suplícios da palavra"10 confirma a validade dessa definição: altere a posição das palavras no poema

Cunha o verso qual moeda:

À risca, nítida, honesta.

Com afinco, siga a regra:

Para que palavras se espremam

E pensamentos tenham fresta. ${ }^{11}$

para convencer-se de que com a perda da forma (nesse caso, a externa) o poema se converte em um "aforismo didático trivial".

Assim, ao perder a "forma", a palavra perfaz o inevitável caminho da poesia à prosa (Potebniá, Iz zapíssok po teorii sloviésnosti ["Das anotações sobre a teoria da literatura"]).

Essa perda da forma da palavra se revela um grande alívio para o pensamento e pode ser uma condição necessária para a existência da ciência, mas a arte não pode se satisfazer com palavras erodidas. Dificilmente seria possível dizer que a poesia recuperou os prejuízos causados pela perda da figuratividade da palavra, substituindo-a por uma criação mais elevada - como, pela criação de tipos -, pois nesse caso ela não teria se agarrado com tamanha avidez à palavra figurada mesmo nos níveis mais elevados de seu desenvolvimento, como fez no período das crônicas épicas. Na arte, o material deve ser vivo, precioso. E assim surge o epíteto; ele não acrescenta nada de novo à palavra, apenas renova a sua falecida figuratividade; por exemplo: sol claro, combatente bravo, face da Terra, ${ }^{12}$ lama movediça, chuva rala. ${ }^{13} \mathrm{~A}$ própria palavra "chuva" encerra uma

10 GORNFELD, A. Muki slova. São Petersburgo, 1906, p. 41. (Nota da edição russa).

11 Versos do poema "Forma", publicado em 1879, do ciclo "À maneira de Schiller", de N. A. Nekrássov. 0 poema original inicia-se com três versos que Chklóvski não citou em seu artigo. A saber: «0 generoso tributo do tempo/ Paga à forma: o que importa no poema/ É que o estilo corresponda ao tema». Traduzido a partir do original: Pólnoie sobraniie sotchnienie i pissem v 15 tomakh [Obra completa e correspondência em 15 tomos]. Leningrad: Naúka, 1982, t. 3. Stikhotvoreniia 1866-1877, p. 214.

12 No original, biéli sviét, expressão russa cujo significado é "Terra".

13 No original driben dojd, expressão inexistente no russo contemporâneo. Remete à expressão ucraniana дрібен дощ, que significa chuva fraca/rala. A palavra russa dróbnost 
ideia de fragmentação, mas a imagem está morta, e a sede de concretude que constitui a alma da arte (Carlyle) exigiu sua renovação. Vivificada pelo epíteto, a palavra se tornou novamente poética. $O$ tempo passou e o epíteto deixou de ser vivenciado, por ter, mais uma vez, se tornado habitual. O epíteto também passou a ser empregado por hábito, por força de tradições escolares e não de um senso poético vivo. Com isso, o epiteto é tão pouco vivenciado que, com bastante frequência, seu uso entra em contradição com a posição geral e o colorido do quadro, por exemplo:

$$
\begin{aligned}
& \text { Não queimas a vela de sebo, } \\
& \text { Vela de sebo, de ardente cera } \\
& \text { (Canção popular) }
\end{aligned}
$$

ou as "mãos brancas" do negro (epos sérvio), "meu amor verdadeiro" das baladas inglesas antigas, que se aplica independentemente de tratar-se de um amor verdadeiro ou não, ou Nestor, que em plena luz do dia ergue os braços em direção ao céu estrelado etc.

Os epítetos recorrentes foram suavizados, não despertam mais uma impressão figurativa e não satisfazem suas exigências. Em suas fronteiras são criados novos epítetos, eles se acumulam, as definições variam conforme as descrições emprestadas do material das sagas ou lendas (Aleksandr Vesselóvski, Iz istorii epiteta ["Da história do epíteto']). Epítetos complexos também se relacionam a épocas posteriores.

"A história do epíteto é a história do estilo poético em versão resumida" (A. Vesselóvski, Sob. sotch., SPB, 1913, v. 1, p. 58). Ela nos revela como todas as formas de arte perecem e, como o epíteto, vivem, se petrificam e, enfim, morrem.

Pouca atenção é dedicada à morte da forma da arte, o novo é levianamente contraposto ao velho, sem pensar se está vivo ou se já desapareceu, como desaparece o barulho do mar para aqueles que vivem no litoral, como desaparece para nós o ru-

[fragmentação, caráter fragmentário], empregada a seguir, tem o mesmo radical do adjetivo driben. Os exemplos desse excerto apresentam epítetos amplamente empregados na língua corrente, mas que são redundantes ou incoerentes em relação ao substantivo qualificado. No caso da chuva, sendo ela mesma um fenômeno formado por gotas (isto é, por fragmento), qualificá-la como "rala" ou "grossa" seria contraditório. 
gido de mil vozes da cidade, como desaparece de nossa consciência tudo que é habitual, demasiado familiar.

Não apenas palavras e epítetos se petrificam, situações inteiras podem sofrer esse mesmo efeito. Como na edição de Bagdá dos contos árabes: o viajante, que foi deixado nu por bandidos, subiu a montanha e, em desespero, "rasgou as próprias vestes". Nesse excerto, todo o quadro se enrijeceu até a inconsciência.

O destino das obras dos antigos artistas da palavra é o mesmo que o destino da própria palavra. Elas perfazem o caminho da poesia à prosa. Deixam de ser vistas e passam a ser reconhecidas. A armadura de vidro do hábito recobre as obras dos clássicos; nós nos lembramos perfeitamente bem delas, ouvimos desde a infância, lemos nos livros, citamos em conversas cotidianas, e agora temos um calo na alma, já não as vivenciamos.

$\mathrm{Eu}$ falo das massas. Muitos pensam que elas vivenciam a arte antiga. Como é fácil se enganar sobre isso! Não à toa Gontcharov comparou ceticamente a vivência do clássico durante a leitura de um drama grego com as vivências de um Petrúchka gogoliano ${ }^{14}$. Penetrar a arte antiga é com frequência impossível. Veja só os livros dos gloriosos conhecedores do classicismo: que vinhetas vulgares, que imagens de esculturas decadentes colocam nas capas! Rodin, que por anos copiou as esculturas gregas, teve que recorrer à medição para dar-lhes forma; acontece que ele o tempo todo as moldou muito sutis. Tamanho gênio não pode reproduzir as formas de outra época. $E$ apenas a leviandade e o rebaixamento das exigências em relação à assimilação do antigo explicam o entusiasmo dos leigos nos museus.

A ilusão de que que a arte antiga é vivenciada sustenta-se pela ideia de que nela frequentemente estão presentes elementos alheios à arte. Tais elementos existem sobretudo na literatura; por isso hoje a literatura é hegemônica na arte e tem maior número de apreciadores. A percepção artística se

14 A citação às Memórias de Gontcharov é imprecisa. (Nota da edição russa). Petrúchka é personagem do romance Almas mortas de Nikolai Gógol. 
caracteriza por nosso desinteresse material. A admiração pelo discurso de um defensor no tribunal não é uma vivência artística e se vivenciamos os pensamentos nobres e humanos dos poetas mais humanistas do mundo, tais vivências já não têm nenhuma relação com a arte. Elas nunca foram poesia, por isso não perfizeram o caminho da poesia à prosa. A existência de pessoas que colocaram Nadson ${ }^{15}$ acima de Tiútchev ${ }^{16}$ também mostra que os escritores com frequência valorizam a quantidade de pensamentos nobres encerrados em suas obras, uma medida, aliás, muito difundida entre a juventude russa. A apoteose da vivência da "arte" do ponto de vista da "nobreza" são os dois estudantes de "O velho professor", de Tchekhov, que se perguntam no teatro: '“O que diz ele? No-o-bre?'. 'É nobre' [...] 'Brravo!'."17

Aqui está dado o esquema da relação entre a crítica e as novas tendências na arte.

Saia na rua e veja os edifícios: como as formas da velha arte são empregadas neles? Vocês verão coisas simplesmente horripilantes! Por exemplo o edifício na Avenida Niévski em frente à Koniúchnaia, uma obra do arquiteto Lialiévitch: arcos semicirculares apoiam-se em pilares e entre os ábacos introduzem-se lintéis, talhados como arcos adintelados. O sistema inteiro possui um espaçamento nas laterais, não há qualquer apoio nos lados, assim, tem-se a nítida impressão de que o edifício está desmoronando e caindo.

Esse absurdo arquitetônico (que não é notado pelo público geral nem pela crítica) não pode ser, nesse caso (e há muitos casos como esse), explicado pela ignorância ou falta de talento do arquiteto.

15 Semión lákovlevitch Nádson (1862-1887), poeta russo cuja obra se inicia com temas sociais e, paulatinamente, se aproxima do individualismo típico dos poetas decadentes do fim do século.

16 Fiódor Ivánovitch Tiútchev (1803-1873), diplomata e poeta do romantismo russo. Sua poesia de caráter meditativo teve como temas principais o cosmos, os motivos existenciais e a natureza.

17 Trata-se do conto "Uma história enfadonha", aqui citado a partir da tradução de Boris Schnaiderman (cf. TCHEKHOV, A. P. O beijo e outras histórias. São Paulo: Editora 34, 2006, p. 156). 
A questão, é óbvio, é que a forma e o sentido do arco (assim como a forma da coluna, o que também pode ser demonstrado) não são vivenciados, e, portanto, ele é empregado de modo tão absurdo como se aplica o epíteto "de sebo" à vela de cera.

Vejamos agora como são citados os autores antigos.

Infelizmente até hoje ninguém compilou as citações incorretas ou fora de propósito - um material curioso. Nas montagens dos dramas dos futuristas, o público gritava "Décima primeira versta", "loucos", "Enfermaria $\mathrm{n}^{\circ}$ 6" e os jornais reproduziam esses brados com satisfação. No entanto, justo em "Enfermaria n. 6" não há loucos, mas um médico aprisionado por ignorantes e mais alguns filósofos sofredores. Dessa forma, a menção à obra de Tchekhov (como é feita pelos que gritam) é completamente fora de propósito. Observamos aqui uma petrificação da citação, por assim dizer, que significa o mesmíssimo que o epíteto petrificado: ausência de vivência (no exemplo dado, a obra inteira foi petrificada).

A grande massa se satisfaz com a arte de mercado, mas esta revela a morte da arte. Antigamente, quando nos encontrávamos, dizíamos uns aos outros "Zdrávstvui!" [Olá!], hoje a palavra morreu, e dizemos apenas "aste". A perna da cadeira, a estampa dos tecidos, o ornamento dos prédios, os quadros da "Sociedade de pintores de São Petersburgo", ${ }^{18}$ as esculturas de Guintsburg:19 tudo isso equivale a "aste". Nesse caso, o ornamento não é construído, mas "narrado", ele conta com o fato de que não o veem, mas reconhecem e dizem: "é este mesmo". A época do florescimento da arte não conhecia a expressão "móvel de feira". Na Assíria, o mastro da tenda de um soldado; na Grécia, a estátua de Hécuba, guardiã do fosso; na Idade Média, ornamentos colocados tão alto que nem se podia vê-los bem, - tudo isso foi feito, tudo isso foi calculado para uma contem-

18 Segundo nota da edição russa, trata-se, na verdade, da Comuna dos Artistas (Obschina khudôjnikov), coletivo fundado em 1908 em São Petersburgo por egressos da Academia Imperial de Artistas, apoiados pelo grande pintor realista Iliá Riépin. Alguns de seus membros foram David Okroiants (1874-1943), Mikhail Kerzin (1883-1979), Tikhon Tchernichóv (1882-1942).

19 Iliá lákovlevitch Guintsburg (1859-1939), escultor e professor da Academia Imperial de Artistas e, posteriormente, dos Vkhutemas. No período soviético, tomou parte no plano de Propaganda Monumental. 
plação apaixonada. Na época em que as formas da arte eram vivas, ninguém enfiava porcarias de feira em casa. Quando no século XVII, na Rússia, cultivou-se a pintura artesanal de ícones, e "começaram a surgir neles arrebatamentos e absurdos tais, que não podiam sequer ser vistos por um cristão", isso significou que as formas antigas já haviam sido ultrapassadas. Agora, a arte antiga já está morta, e a nova ainda não nasceu; até as coisas morreram: perdemos a sensação do mundo, mais parecemos um violinista que já não sente o arco e as cordas; deixamos de ser artistas na vida cotidiana, não amamos nossas casas nem nossas roupas, facilmente nos afastamos da vida, a qual já não sentimos. Apenas a criação de novas formas de arte pode devolver ao homem a vivência do mundo, ressuscitar as coisas e matar o pessimismo.

Quando num acesso de ternura ou maldade intentamos agradar ou ofender alguém, e temos poucas palavras gastas e roídas para fazê-lo, começamos a amarfanhar e despedaçar as palavras, de modo que elas atinjam o ouvido, que sejam vistas e não reconhecidas. Chamamos, por exemplo, um homem de "mula"20 para que a palavra arranhe; ou o povo simples ("O escritório", de Turguêniev) ${ }^{21}$ que usa o gênero feminino ao invés do masculino para expressar ternura. Estão relacionadas a esse fenômeno um sem-número de palavras simplesmente deformadas tão usadas por nós em momentos de afeto, das quais temos dificuldade de nos recordar.

E agora, hoje, quando o artista quer lidar com a forma viva e com a palavra viva, e não morta, ao pretender dar-lhe um rosto, ele a destrói e deforma. Nasceram as palavras "arbitrárias" e "derivadas" dos futuristas. Eles ora criam novas palavras a partir de radicais antigos (Khlébnikov, Gurô, Kamiénski, Gniédov), ora as cindem pela rima, como Maiakóvski, ora imprimem um ritmo ao verso a partir de tônicas incorretas (Krutchônykh). $\mathrm{O}$ antigo fulgor retorna aos velhos diamantes das palavras. Essa nova língua é incompreensível, difícil, não

20 No original 0 autor emprega o adjetivo dura [tola], feminino de durak.

210 conto faz parte do volume Memórias de um caçador, de Ivan Turguêniev (tradução de Irineu Franco Perpétuo. São Paulo: Editora 34, 2017, p. 179-200). 
pode ser lida como o jornal Birjevka. ${ }^{22}$ Nem parece russo, mas nós estamos demasiadamente acostumados a colocar a inteligibilidade como uma exigência da língua poética. A história da arte nos mostra (com certa frequência) que a língua da poesia não é inteligível, mas semi-inteligível. Assim, os selvagens costumam cantar em língua arcaica ou estrangeira, às vezes tão incompreensível que o cantor (mais exatamente o cantor principal) precisa traduzir e explicar ao coro e aos ouvintes o significado da complexa canção (A. Vesselóvski, Tri glavy iz istoritcheskoi poetiki [Três capítulos de história poética]; E. Grosse, Origens da Arte.).

A poesia religiosa de quase todos os povos foi escrita em tal língua semi-inteligível. Eslavo eclesiástico, latim, sumério (idioma morto no século XX antes de Cristo e empregado como língua religiosa até o século III), o alemão entre os russos chtundistas $^{23}$ (por muito tempo, em vez de traduzir os hinos religiosos alemães para o russo, eles preferiram aprender alemão. Dostoiévski, Diário de um escritor).

J. Grimm, Hoffmann e Hebel ${ }^{24}$ notam que o povo simples costuma cantar não no dialeto, mas em uma língua elevada, próxima da literária; "a língua iacuta de canto se distingue da de uso corrente quase tanto quanto a língua eslava e a nossa língua coloquial presente" (Koroliénko, At-Davan); Arnaut Daniel, ${ }^{25} \mathrm{com}$ seu estilo sombrio e formas artísticas difíceis (schwere Kunstmanier), formas duras (harte), que impõem dificuldade à pronúncia (Diez, Leben und Werk der Troubadours, $\mathrm{p}$.

22 Birjevíe viédomosti (Registro da Bolsa de Valores), revista de política e economia, de tendência liberal, publicada em São Petersburgo entre 1880 e 1917.

23 Os chtundistas eram grupos evangélicos protestantes que surgiram entre camponeses ucranianos no sudoeste do Império Russo na segunda metade do século XIX. O nome tem origem na palavra alemã Stund (hora), e está ligado ao costume de reservar uma hora diária ao estudo da Bíblia.

24 Jacob Grimm (1785-1863), autor, junto do irmão Wilhelm Grimm, de coletâneas de contos de fadas. E. T. A. Hoffmann (1776-1822), um dos mais conhecidos autores de literatura fantástica. Johann Peter Hebel (1860-1826), poeta do dialeto alemânico e autor de histórias de almanaque.

25 Arnaut Daniel foi um trovador occitano que produziu entre os anos 1180 e 1200 . Seu estilo, elogiado por Dante Alighieri, se caracterizava por obscuridade, emprego de palavras pouco familiares e alusões enigmáticas. Sua obra é comentada pelo filólogo alemão Friedrich Christian Diez, citado por Chklóvski a seguir. 
285); o dolce stil nuovo (século XII) italiano: todas elas são línguas semi-inteligíveis. Aristóteles na Poética (cap. 23) sugere dar à língua um caráter estrangeiro. A explicação para esses fatos consiste em que essa língua semi-inteligível, em virtude de seu caráter inabitual, parece mais figurativa ao leitor (como observado, aliás, por D. N. Ovsiániko-Kulikóvski).

Os escritores de ontem escreviam com demasiada suavidade, demasiada doçura. As coisas parecem-lhes as superfícies lustradas das quais falava Korolenko: "Por ela corre a plaina do pensamento sem esbarrar em nada". É preciso criar algo novo, "penoso" (palavra de Krutchônykh) ${ }^{26}$ para a visão, não para o reconhecimento de uma língua calculada. E essa necessidade é sentida inconscientemente por muitos.

Os caminhos da nova arte estão apenas delineados. Caberá aos artistas, não aos teóricos, caminhar à frente de todos. Serão os futuristas a criarem as novas formas ou há outros destinados a essa façanha? De todo modo, os poetas-vindourianos $^{27}$ estão no caminho certo: eles avaliaram corretamente as formas antigas. Seus procedimentos poéticos, procedimentos do pensamento verbal geral, foram introduzidos por eles na poesia, assim como nela foi introduzida nos primeiros séculos do Cristianismo a rima, que, de certo, sempre existiu na língua.

A tomada de consciência dos novos procedimentos criativos encontrados por acidente nos poetas do passado (por exemplo, os simbolistas) - já é um grande feito. E isso foi realizado pelos vindourianos. ${ }^{28}$

Recebido em: 04/07/2020

Aceito em: 30/07/2020

Publicado em setembro de 2020

26 KRUTCHÔNYKH, A.; KHLÉBNIKOV, V. Slovo kak takovoe [A palavra como tal]. São Petersburgo, 1913, p. 3. (Nota da edição russa).

270 termo russo budetliáne, cunhado por Krutchônykh, foi aqui vertido como "vindouriano". 0 neologismo origina-se da forma futura do verbo "ser" (budut) associada a um sufixo que, em geral, indica proveniência, origem (como -ano em português). Essa tradução por decalque costumava ser empregada pelos poetas futuristas em preferência ao vocábulo de origem latina (futurist), e deu nome a um manifesto escrito por Vladímir Maiakóvski em 1914.

280 manuscrito encerrava-se com a seguinte frase: " 0 caminho deles está correto, e se eles perecerem antes de chegar ao destino final, perecerão em um grandioso empreendimento". (Nota da edição russa). 